\title{
Are bio-telemetric devices a drag? Effects of external tags on the diving behaviour of great cormorants
}

\author{
S. P. Vandenabeele ${ }^{1, *}$, E. L. C. Shepard ${ }^{1}$, D. Grémillet ${ }^{2,3}$, P. J. Butler ${ }^{4}$, G. R. Martin ${ }^{4}$, \\ R. P. Wilson ${ }^{1}$ \\ ${ }^{1}$ Swansea Lab for Animal Movement, Biosciences, College of Science, Swansea University, Singleton Park, Swansea, UK \\ ${ }^{2}$ Centre d'Ecologie Fonctionnelle et Evolutive, CNRS UMR 5175, Montpellier, France \\ ${ }^{3}$ DST/NRF Centre of Excellence, Percy FitzPatrick Institute, University of Cape Town, South Africa \\ ${ }^{4}$ Centre for Ornithology, School of Biosciences, University of Birmingham, Birmingham, UK
}

\begin{abstract}
Externally attached remote-sensing devices used to study animals in their environment are a possible source of disturbance, notably in terms of drag, for diving species. The aim of the present study was to assess the possible effect of device-induced drag on the diving performance of great cormorants Phalacrocorax carbo. Based on wind-tunnel measurements, we assessed the effect of device size on drag and derived a formula to predict how drag changes as a function of both swim speed and device cross-sectional area. Tests on captive cormorants indicated that drag had an effect on the energy expenditure (using dynamic body acceleration as a proxy) during the dive. Wind tunnel-derived drag metrics were combined with data from the literature to construct a model predicting the power consumption of diving cormorants according to device size. Applying the model to dive data from 6 free-living great cormorants (recorded using implanted time-depth recorders) indicated that a device constituting only ca. $3 \%$ of the bird's cross-sectional area could cause a $1.7 \%$ increase in power consumption when swimming. However, if a bird maintains constant power underwater, e.g. by decreasing foraging speed with increasing drag, this would result in a $7.1 \%$ reduction in the distance travelled during the bottom (active hunting) phase of the dive. Device-related increases in drag are also likely to reduce the maximum speeds achievable by these pursuit predators. The present study highlights the interaction between both drag coefficient and swim speed for diving animals with externally attached devices.
\end{abstract}

KEY WORDS: Bird · Foraging $\cdot$ Data-logger $\cdot$ Transmitter $\cdot$ Hydrodynamics $\cdot$ Swimming energetics

\section{INTRODUCTION}

Externally attached devices such as biologgers have transformed the way ecologists study animals, allowing them to investigate the positions and movements of animals in the wild and to relate these to the environmental characteristics (Cooke et al. 2004, Ropert-Coudert \& Wilson 2005, Rutz \& Hays 2009). However, the possible impact that external devices could have on the animals, an aspect that has been particularly well documented for birds in recent years (e.g. Wilson et al. 1986, Calvo \& Furness 1992, Barron et al. 2010, Vandenabeele et al. 2011), is cause for concern. A recent study examining the effect of flipper bands on penguins over $10 \mathrm{yr}$ found that the small, seemingly inoffensive, identification bands can affect population processes (Saraux et al. 2011). The study determined that flipper-banded king penguins Aptenodytes patagonicus had 39\% lower breeding success and $16 \%$ lower survival rate 
than unequipped conspecifics over the decadal study period. The exact cause for this effect is unknown, but indirect calorimetry work on Adélie penguins Pygoscelis adeliae in a swim canal indicates that it may be energy-based, because the addition of a flipper band caused metabolic power requirements for normal underwater swimming to increase by $24 \%$ (Culik et al. 1993). The extremely low drag coefficient of penguins $(0.003$, the lowest determined for any bird ${ }_{i}$ Clark \& Bemis 1979) may explain how such small external objects impacted the carriers so profoundly. Thus, although it appears that small external bodies should have minimal or no effect, the actual increase in turbulence in the water flow, or drag, can be relatively substantial (Culik \& Wilson 1991, Bannasch 1995).

The drag caused by external bodies attached to animals has been measured by a relatively small number of studies. Obrecht et al. (1988) and more recently Bowlin et al. (2010) examined the effect of the form and size of external devices on the drag of different bird species, using models in a wind tunnel. Pennycuick et al. (2012) reported a dramatic increase in drag for harness-equipped common starlings Sternus vulgaris during flight in a wind tunnel. A similar approach, using water instead of air, was adopted by Watson \& Granger (1998) to assess the impact of external devices on swimming turtles, while Wilson et al. (2004) used model penguins moving up a swim channel to determine the drag associated with the presence of external antennae. Ideally, however, such studies need to be expanded to include free-living animals so as to put their findings into a behavioural and ecological context.

To achieve this, we determined the drag of various devices on a model great cormorant Phalacrocorax carbo in a wind tunnel, and then used the same devices on great cormorants trained to swim underwater in a defined experimental set-up. Measurements of swim speed can be combined with loggerrecorded depth and tri-axial acceleration so that bird energetic response and performance can be assessed in relation to drag, using overall dynamic body acceleration (ODBA) as a qualitative proxy for the metabolic rate associated with movement (Wilson et al. 2006, Green et al. 2009, Halsey et al. 2009, Gleiss et al. 2011, Elliott et al. 2013). In the present study we consider how external devices of defined drag might impact the behavioural ecology of foraging wild birds, using data derived from great cormorants implanted with time-depth recorders (see Grémillet et al. 2005 for details). In this we focus on the critical bottom phase of the dive, when most of the foraging activity occurs. Amongst the main effects expected to emerge as a result of the drag associated with external devices fitted to swimming birds are (1) a reduction in swim speeds to maintain the power costs at same level as during unequipped swimming, and (2) an increase in energy expenditure associated with maintaining the same swim speeds as in unequipped birds.

These 2 hypotheses are not mutually exclusive. Our investigation goes further than simply observing device effects by developing a method to quantify them. Ultimately there is a need to assess the behavioural responses of animals equipped with any form of instrumentation in order to quantify the likely impact on an animal's foraging efficiency and energetic outlay, as these are the mechanisms by which devices may ultimately affect population-level processes.

\section{MATERIALS AND METHODS}

\section{Wind tunnel measurements}

We conducted wind tunnel experiments in the Swansea University engineering facility which houses a unit that provides laminar air flow for speeds up to $28 \mathrm{~m} \mathrm{~s}^{-1}$ (see Orme et al. 2001 for details). A wooden (pine) model of a great cormorant was handcrafted in the underwater swimming position based on attitudes of diving birds taken from photos and videos and using dimensions provided by the frozen carcass of an adult bird. The $925 \mathrm{~g}$ model was secured in the wind tunnel test section using 3 supporting struts (Fig. 1) connected to a balance system that measured the drag experienced by the model. The drag force was first measured over a range of model body

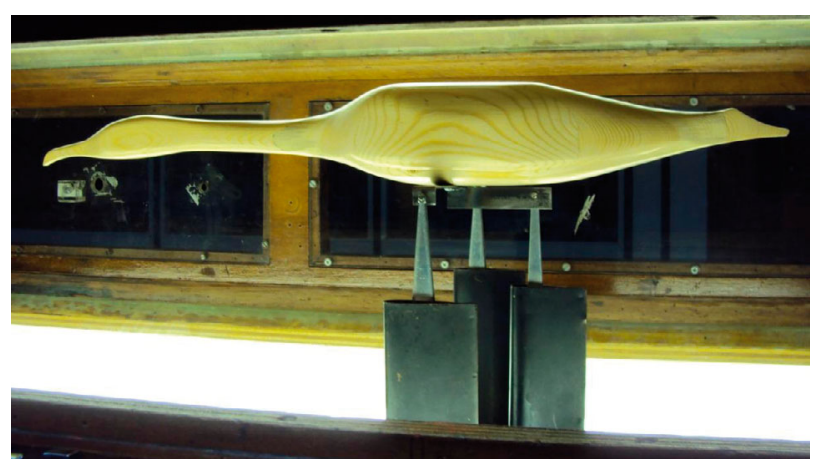

Fig. 1. Wooden model of a great cormorant Phalacrocorax carbo mounted on 3 struts in the test section of a wind tunnel (Swansea University facility, UK). The struts are connected to balances that allow measurement of the drag experienced by the bird model when exposed to various air speeds (emulating the swim and/or flight speeds of the species) 
Table 1. Examples of device size (cross-sectional area) fitted on various seabirds, including cormorants, and bottomphase swim speeds recorded for great cormorants Phalacrocorax carbo, gathered from the literature. NA: not available; Avg.: average; Max.: maximum

\begin{tabular}{|c|c|c|}
\hline Study & $\begin{array}{l}\text { Device } \\
\text { size }\left(\mathrm{cm}^{2}\right)\end{array}$ & $\begin{array}{l}\text { Swim speed } \\
\left(\mathrm{m} \mathrm{s}^{-1}\right)\end{array}$ \\
\hline Paredes et al. (2005) & $1.7-1.9$ & NA \\
\hline $\begin{array}{l}\text { Tremblay et al. (2005), } \\
\text { Watanuki et al. (2006) }\end{array}$ & 2 & NA \\
\hline Watanuki et al. (2008) & 3.46 & NA \\
\hline $\begin{array}{l}\text { Ropert-Coudert et al. } \\
\text { (2006) }\end{array}$ & 3.14 & $\begin{array}{l}\text { Avg.: } 0.8 \\
\text { range: } 0.2-4\end{array}$ \\
\hline Grémillet et al. (2003) & NA & 1.35 \\
\hline $\begin{array}{l}\text { Voslamber \& Van } \\
\text { Eerden (1991) }\end{array}$ & NA & 1.4 \\
\hline Wilson \& Wilson (1988) & NA & $\begin{array}{l}\text { Depth dependent, } \\
\text { range: } 0.2-4\end{array}$ \\
\hline Ross (1976) & NA & Max.: 3 \\
\hline
\end{tabular}

angles to define the angle where this was at the minimum before setting the model in this position for further trials. The balance was calibrated using standard masses and all readings for drag were transformed into force $(\mathrm{N})$.

The drag on the model (without device) was determined for a range of air speeds that emulated swimming speeds displayed by great cormorants in the wild (from $\sim 0.2$ to $\sim 1.8 \mathrm{~m} \mathrm{~s}^{-1}$, Ropert-Coudert et al. 2006; see Table 1). The air speeds corresponded to the Reynolds number (Re) equivalent to that of the required swimming speeds, thus compensating for the different viscosities of air and water. Measurements were then made from the model fitted with 4 different device sizes (the same as in the experimental set-up with live birds, see 'Captive bird trials' below). Devices were constructed from polyurethane foam with a cuboid shape, equivalent height to width ratio (0.56), and cross-sectional areas of 7.88 to $11.25 \mathrm{~cm}^{2}$ (Table 2). Devices were attached to the lower back of the model bird, as recommended by Bannasch et al. (1994), and this same position was used for the captive cormorant trials (see 'Captive bird trials' below). The results from this experimental phase were later combined with published data to develop a method to help quantify the power required for the bird to swim as a function of drag.

\section{Captive bird trials}

Six adult great cormorants weighing between 1.77 and $2.79 \mathrm{~kg}$ were used for the captive bird trial. They
Table 2. Dimensions and frontal cross-sectional area of the different-sized devices used in wind tunnel tests and deployed on captive great cormorants. For device orientation, the dimensions Length and Height define the plane conventionally described by $x$ and $y$, respectively

\begin{tabular}{|lccccc|}
\hline $\begin{array}{l}\text { De- } \\
\text { vice }\end{array}$ & $\begin{array}{c}\text { Length } \\
(\mathrm{cm})\end{array}$ & $\begin{array}{c}\text { Width } \\
(\mathrm{cm})\end{array}$ & $\begin{array}{c}\text { Height } \\
(\mathrm{cm})\end{array}$ & \multicolumn{2}{c|}{$\begin{array}{c}\text { Cross-sectional area } \\
\left(\mathrm{cm}^{2}\right)\end{array}$} \\
& & & & $\begin{array}{c}\text { \% of cross- } \\
\text { section } \\
\text { of the bird })\end{array}$ \\
\hline 1 & 8.30 & 3.75 & 2.10 & 7.88 & 6.3 \\
2 & 8.30 & 3.90 & 2.20 & 8.58 & 6.8 \\
3 & 8.30 & 4.30 & 2.40 & 10.32 & 8.2 \\
4 & 8.30 & 4.50 & 2.50 & 11.25 & 9.0 \\
\hline
\end{tabular}

were housed communally in a $130 \mathrm{~m}^{2}$ outdoor aviary at the Edgbaston campus at Birmingham University. Details of bird care are given in White et al. (2007). The cormorants had been previously trained to swim through an underwater channel $2.8 \mathrm{~m}$ long fashioned from stainless steel grating and sunk in a $1 \mathrm{~m}$ deep, $8 \times 4 \mathrm{~m}$ tank (White et al. 2007) that was continuously replenished with freshwater.

Cormorants were equipped with the same polyurethane foam units (Table 2) attached with Tesa tape (Wilson \& Wilson 1989) to the same lower-back position as used in the wind tunnel drag tests. The polyurethane blocks had been constructed with a hollow to house small multiple-channel loggers (5.6 $\times$ $2.4 \times 1.5 \mathrm{~cm}$; total mass in air $19.7 \mathrm{~g}$ ). These loggers were set to record tri-axial acceleration (in the dorso-ventral, anterior-posterior, and lateral axes) and depth at $12 \mathrm{~Hz}$, with absolute accuracies of $>0.05$ $\times g$ and $0.02 \mathrm{~m}$, respectively. The combined unit of logger + polyurethane foam was made neutrally buoyant in freshwater by adding small lead weights where necessary. During trials, the time taken for a bird to swim through the $2.8 \mathrm{~m}$ straight section of the channel was determined using a stopwatch, and the procedure was filmed. The birds performed between 0 and 30 runs per day over 6 consecutive days and each of the 4 differently sized units was tested on each individual bird.

Speed, rate of change of depth, duration and total overall dynamic body acceleration (ODBA) were calculated for all dives, along with the descent and ascent durations (see Halsey et al. 2007 for definition). ODBA correlates well with energy expenditure in moving animals (Wilson et al. 2006, Green et al. 2009, Halsey et al. 2009, Gleiss et al. 2011, Elliott et al. 2013) and was determined by a 3 stage process: (1) the running mean over $2 \mathrm{~s}$ for each of the 3 orthogonal acceleration channels was used to 
determine the static acceleration from the signal (Shepard et al. 2008); (2) the static acceleration values were subtracted from the raw acceleration recorded for each channel to derive the dynamic acceleration (Wilson et al. 2006), and (3) the dynamic values were made positive and summed (Gleiss et al. 2011).

\section{Free-living bird data}

Dive data from 6 great cormorants breeding on Disko Island, West Greenland $\left(69^{\circ} 30^{\prime} \mathrm{N}, 54^{\circ} 05^{\prime} \mathrm{W}\right)$ equipped with implanted data loggers (see Grémillet et al. 2005 for details) were used to quantify the variation in dive parameters as a function of maximum depth. These data were assumed to be representative of the normal behaviour of birds in the wild, since implanted devices impose none of the drag constraints incurred with externally attached devices (e.g. Green et al. 2004, Ritchie et al. 2010). Dive parameters, including bottom duration and maximum depth, were calculated for 20 dives from each bird (120 dives in total). Particular attention was paid to the critical bottom phase of the dive, when most of the feeding activity occurs. The correlation between bottom duration and maximum depth was determined and then used to simulate the effect of drag on unequipped versus equipped birds during the bottom phase.

Analyses were performed using Origin (v. 8.5.1, OriginLab, USA). All statistical tests were carried out using SPSS (SPSS $®$ Release 16.0.1 v. 2007) and p < 0.05 was considered statistically significant.

\section{RESULTS}

\section{Wind tunnel measurements}

There was a clear and significant increase in drag with swim speed for the model cormorant equipped with variously sized devices (Fig. 2). The relationships between swim speed $\left(V, \mathrm{~m} \mathrm{~s}^{-1}\right)$ and $\operatorname{drag}\left(F_{\mathrm{D}}\right.$, $\mathrm{N})$ according to device size were: bird model only, $F_{\mathrm{D}}=0.0073+0.5494 \mathrm{v}^{2} ;$ model with Device $1, F_{\mathrm{D}}=$ $0.0041+0.7042 v^{2}$; with Device 2, $F_{\mathrm{D}}=0.0042+$ $0.7591 v^{2} ;$ with Device 3, $F_{\mathrm{D}}=0.0039+0.7751 v^{2}$; with Device $4, F_{\mathrm{D}}=0.0042+0.7990 v^{2}($ all $\mathrm{p}<0.001)$. Larger devices elicited higher drag values for any given swim speed (Fig. 2). We found no relationship between device cross-sectional area and the intercepts from the relationship between drag and swim speed ( $p>0.05)$, but a very clear linear relationship between the coefficients of these relationships $(m)$ and device cross-sectional area $\left(X_{\mathrm{s}} \mathrm{cm}^{2}\right)$ described by $m=0.0222 X_{\mathrm{s}}+0.5482\left(\mathrm{r}^{2}=0.97, \mathrm{p}=0.001\right)$. Thus, the relationship between drag and speed as a function of device cross-sectional area could be given by:

$$
F_{\mathrm{D}}=\left(0.0222 X_{\mathrm{s}}+0.5482\right) v^{2}
$$

assuming the intercept to be 0 , given there was no significant relationship.

\section{Captive bird trials}

The 6 captive cormorants conducted a total of 233 dives, with individuals executing between 5 and 88 dives. This variation in the number of dives was primarily due to some individuals showing clear avoidance behaviour towards repeated capture for the fitting of the different devices. Thus, we pooled all data rather than performing extensive analysis at the individual level. Mean swim speed for individual birds varied between 1.02 and $1.28 \mathrm{~m} \mathrm{~s}^{-1}$. For the dive descent and ascent phases, the increase in device size resulted in a significant decrease in the rate of change of depth (Pearson's correlation test, descent: $\mathrm{N}=233, \mathrm{r}^{2}=0.13, \mathrm{p}<0.001$; ascent: $\mathrm{N}=233, \mathrm{r}^{2}=0.08$, $\mathrm{p}<0.001$ ), but did not have a significant effect on the ODBA.

However, calculation of the overall drag (obtained using the regressions performed between the swim

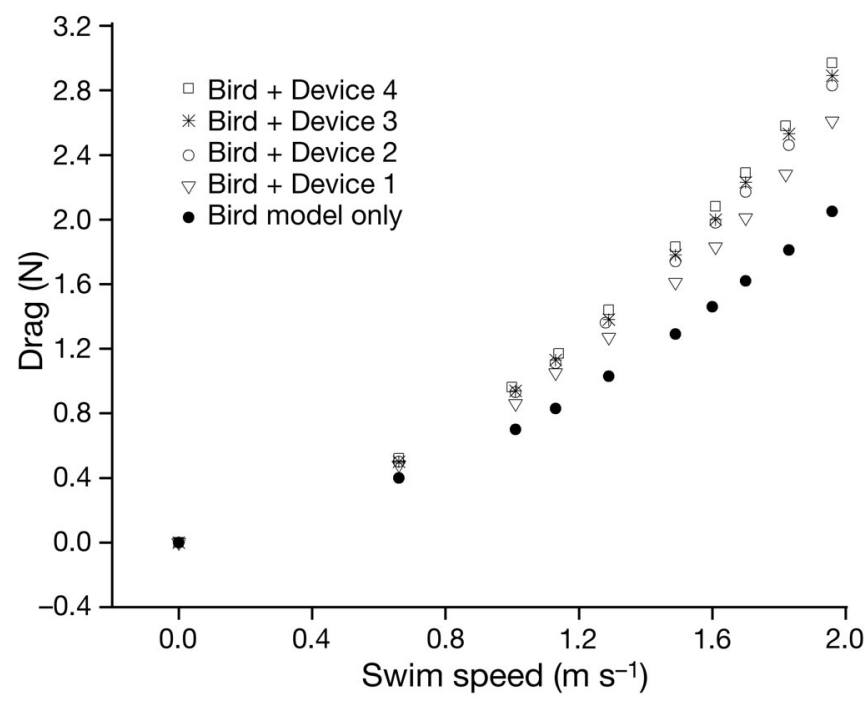

Fig. 2. Drag on a model of a great cormorant with differentsized devices attached (for device sizes see Table 2), as a function of swim speed. Each data point represents the mean of 3 trials 
speed and the drag for the different sized squares Eq. [1]) showed a significant effect, with increasing (mean) ODBA with drag for the entire dive given by:

$$
\mathrm{ODBA}_{\text {dive }}=0.14 F_{\mathrm{D}}+0.46
$$

$\left(\mathrm{N}=233, \mathrm{r}^{2}=0.07, \mathrm{p}<0.001\right)$ and increasing (mean) ODBA with drag for the descent phase given by:

$$
\mathrm{ODBA}_{\text {descent }}=0.24 F_{\mathrm{D}}+0.53
$$

$\left(\mathrm{N}=233, \mathrm{r}^{2}=0.08, \mathrm{p}<0.001\right)$, although both relationships had notably little of their variation explained by this. No significant effect was found between drag and ODBA for the ascent phase of the dive.

\section{Combining data from wind tunnel tests with published data}

We derived an equation relating power consumption to drag, based on the relationship found between drag $\left(F_{\mathrm{D}}\right)$ and swim speed $(v)$ for an unequipped bird (see 'Wind tunnel measurements' above):

$$
F_{\mathrm{D}}=0.5494 v^{2}+0.0073
$$

and the calculations by Schmid et al. (1995), which give the power input $\left(P_{\mathrm{i}}\right)$ of great cormorants swimming in a water canal as a function of swim speed:

$$
P_{\mathrm{i}}=3.6 v^{3}-12.2 v^{2}+21.5 v+P_{\mathrm{r}}
$$

where $P_{\mathrm{r}}$ is the power consumption of the bird resting at the water surface, which is equal to $14.1 \mathrm{~W} \mathrm{~kg}^{-1}$.

Plotting $P_{\mathrm{i}}$ against $F_{\mathrm{D}}$ for different speeds for an unequipped bird gives the relationship:

$$
\begin{aligned}
& P_{\mathrm{i}}=28.72+1.31 F_{\mathrm{D}}^{2} \\
& \left(\mathrm{r}^{2}=0.99, \mathrm{p}<0.001\right)
\end{aligned}
$$

The previously derived equation that relates drag to cross-sectional area and swim speed (Eq. 1) becomes, after simplification:

$$
P_{\mathrm{i}}=28.72+\left[1.31\left(0.0222 X_{\mathrm{s}} v^{2}+0.5482 v^{2}\right)\right]^{2}
$$

The estimations for the power consumption of an unequipped bird as a function of speed found using Eq. (7) or that of Schmid et al. (1995) (Eq. [5]) appeared to be in good agreement (Fig. 3). Eq. (7) therefore can be used to estimate the power consumption of cormorants wearing different-sized devices based on cross-sectional areas of external units commonly used on cormorants $(1,2$ and $4 \mathrm{~cm}^{2}$ ) and swimming speeds up to $4 \mathrm{~m} \mathrm{~s}^{-1}$ (which includes device dimensions and swim speeds found in the literature; Table 1).

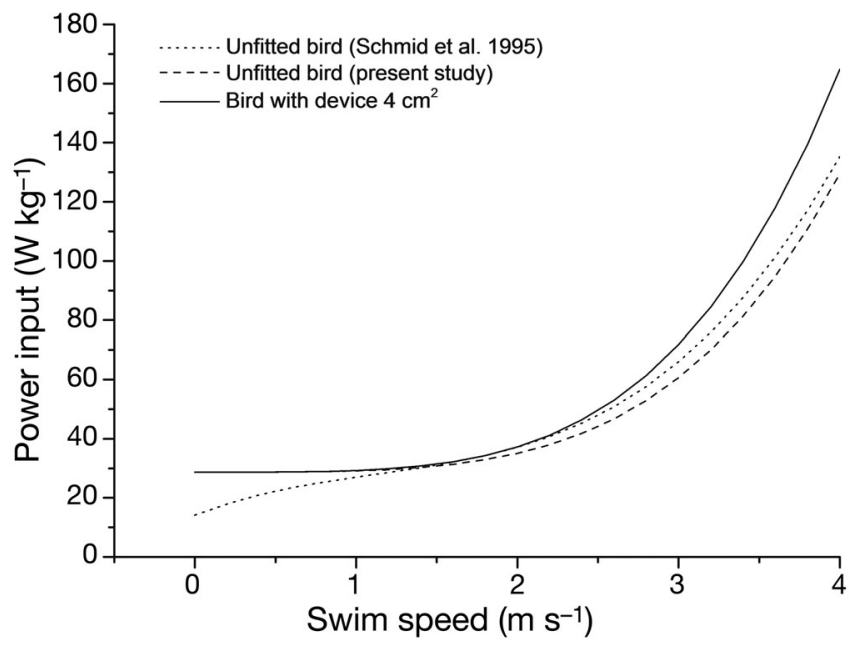

Fig. 3. Energy consumption of a great cormorant swimming underwater as a function of speed derived from the equation from Schmid et al. (1995) [Eq. (5)] in comparison to the values obtained using Eq. (7), derived in this study. Eq. (7) relates power input to speed and cross-sectional area of a device and can therefore be used to estimate the energy spent by great cormorants wearing any kind of device when swimming underwater

\section{Free-living bird data}

All dive parameters showed a linear relationship with maximum depth $(D, \mathrm{~m})$ except for the bottom duration (BT, s), where a second-degree polynomial best described the relationship with maximum depth reached during the dive (Fig. 4 ):

$$
\mathrm{BT}=-0.3882 D^{2}+6.5752 D+3.1797
$$

\section{DISCUSSION}

Since the use of externally attached devices such as biologgers is intended to help scientists elucidate the behaviour of animals in their environment, it is crucial to ensure that this approach does not compromise the animals. Indeed, the potential disturbance that externally attached devices can cause to fitted individuals can lead to a biased representation of their normal behaviour. It is therefore imperative to understand the way devices can affect animals and to ultimately minimise this impact. Although it is acknowledged that devices need to be small, lightweight and streamlined to reduce possible effects, there is a need to quantify these effects to inform studies. The present study features a refined quantitative assessment of the impact of external electronic tags on a diving bird, the great cormorant, in terms of drag and energetics. 


\section{Response of swimming birds to increasing device size}

The results from our captive trials did not appear to be as clear as expected, primarily due to the limitations of the experimental set-up, which did not allow a thorough assessment of the diving behaviour of birds that habitually dive to depths in excess of $10 \mathrm{~m}$. However, some changes occurred in the swimming behaviour of the captive cormorants that could be attributed to the presence of external devices. There were slower rates of change of depth during the descent and ascent phases and based on the power proxy derived from acceleration, ODBA (Wilson et al. 2006, Green et al. 2009, Halsey et al. 2009, Gleiss et al. 2011, Elliott et al. 2013), an apparently fairly small impact of drag on the energetics during the active, descent and bottom phases of the dive. Although this effect is dissipated in the observed variability and was likely masked by the limitations of the experimental set-up (see below), it is likely that in the wild, when birds dive to much deeper depths, the problem would be exacerbated. Support for this is given by the clear increase in drag with device size evident from the wind tunnel measurements (Fig. 2). Among the factors that could explain this are (1) the relatively short distance that our experimental laboratory birds had to travel underwater $(2.8 \mathrm{~m})$, which will tend to increase 'boundary' errors, such as the amount of spring that birds put into initiating their dive (cf. Wilson et al. 1992) and therefore the speed at which they first begin their descent, and (2) the marked ability of cormorants to adjust inhaled air volumes for dives (cf. Sato et al. 2002), profoundly affecting buoyancy and therefore the energy used to dive (cf. Wilson \& Zimmer 2004). Therefore, in con-

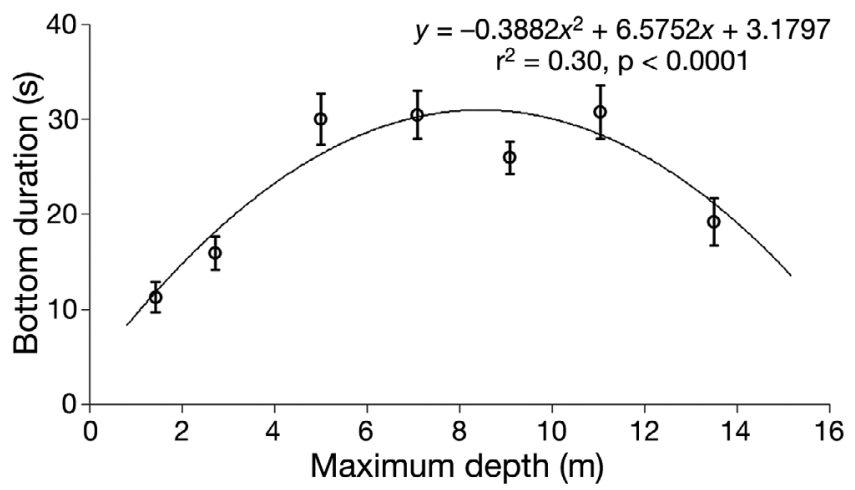

Fig. 4. Relationship between time spent at the bottom and the maximum depth reached by free-living great cormorants Phalacrocorax carbo; grouped by bins with an interval of $2 \mathrm{~m}$ depth. Data were collected using internal loggers (Grémillet et al. 2005) trast to ODBA data derived from wild birds, which concur very closely with predicted energy expenditure scenarios (Wilson et al. 2006, Gómez-Laich et al. 2011), we conclude that the use of ODBA as a metric for determining the effects of external tags on the energetics of laboratory cormorants shows too much variation to be properly descriptive (cf. Enstipp et al. 2011).

\section{Effect of attached devices on the foraging of birds}

Consequently, we combined the results from the wind tunnel experiments on the drag associated with external devices with data from a previous study (Schmid et al. 1995), which had examined the power consumption of cormorants swimming in a water canal, in order to model how external devices might affect the energetics of swimming cormorants. We thus derived an equation that linked power input from diving cormorants with swim speed and device size (Eq. 7). We now use this equation together with data from wild great cormorants diving with dragfree internal devices, to examine the extent to which external devices may affect foraging performance. In this, for simplicity, we concentrate on the bottom phase of the dive, ignoring descent and ascent phases (where buoyancy effects tend to dominate rather than drag; Lovvorn 1999, Watanuki et al. 2003, Wilson et al. 2011). The bottom phase of the dive is also the period where great cormorants specifically engage in foraging for their benthic prey (Wilson \& Wilson 1988, Wanless et al. 1993, Grémillet et al. 1999).

Three different scenarios are explicitly examined: (1) the energetic costs and bottom durations that result from cormorants maintaining a given swim speed while carrying different-sized devices, (2) the distance penalty incurred by cormorants maintaining constant power costs by modulating speed while swimming with different-sized devices, and (3) the capacity for burst swimming in prey capture for cormorants wearing different-sized devices.

\section{Scenario 1: Consequences of maintaining bottom speed}

Great cormorants underwater swim at a variety of speeds (see data summarized in Table 1) but normal values appear to be of the order of 0.8 to $1.4 \mathrm{~m} \mathrm{~s}^{-1}$. We can use Eq. (7) to calculate the power requirements of unequipped birds to swim at these 2 (range limits) speeds and compare them to the power requirements 
of birds swimming at the same speeds wearing differently sized devices (we chose cross-sectional areas of 1,2 and $4 \mathrm{~cm}^{2}$ ) covering the range of dimensions common to devices that are used on cormorants (see Table 2). Here, the power increments to swim at speeds of 0.8 and $1.4 \mathrm{~m} \mathrm{~s}^{-1}$, even while wearing the large $\left(4 \mathrm{~cm}^{2}\right.$ cross-sectional area) devices, were only predicted to be between 0.2 and $1.7 \%$ higher than unequipped birds (28.94 and $30.76 \mathrm{~W}$ compared to 28.88 and $30.23 \mathrm{~W}$, respectively). Assuming that wild, unequipped great cormorants have bottom durations that vary with depth according to Eq. (8), we can calculate the energy spent during the bottom phase by birds if they swim at 0.8 and $1.4 \mathrm{~m} \mathrm{~s}^{-1}$ by multiplying bottom duration by power requirements. Subsequently, assuming that device-equipped birds use the same total amount of energy during the bottom phase, we can calculate the length of time that these birds would spend during the bottom phase of their dives to varying depths. Again, this process showed minimal differences between equipped and unequipped cormorants (amounting to a maximum of $1.72 \%$ ), equating to bottom durations being reduced by less than $1 \mathrm{~s}$, even if the equipped birds are wear-
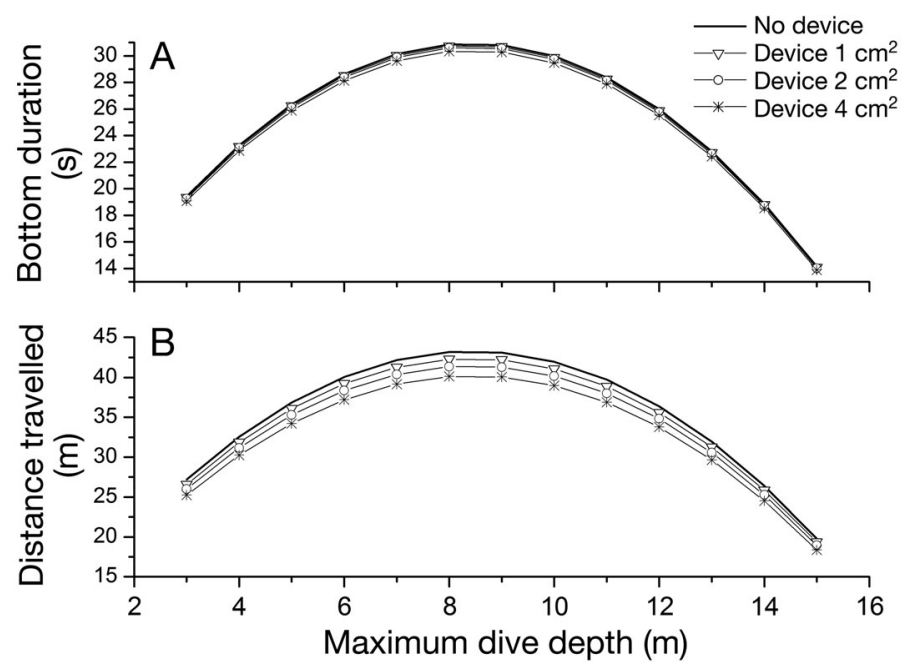

Fig. 5. (A) Predicted duration that great cormorants equipped with different-sized devices would spend during the bottom phase, assuming they maintain their travel speed irrespective of device size, and thereby vary their power requirements (see 'Discussion: Effect of attached devices on the foraging of birds: Scenario 1'). (B) Predicted distance travelled during the bottom phase of dives to different depths, made by great cormorants equipped with different-sized devices, assuming they change speed so as to maintain constant power requirements. Continuous bold lines: predicted values for an unequipped bird swimming at $1.4 \mathrm{~m} \mathrm{~s}^{-1}$; lines with triangles, circles and stars: predicted values from birds wearing devices with cross-sectional areas of 1,2 and $4 \mathrm{~cm}^{2}$ and swimming at $1.37,1.34$ and $1.30 \mathrm{~m} \mathrm{~s}^{-1}$, respectively ing larger devices and swimming at the higher speeds (Fig. 5A).

The increasing and then decreasing form of the bottom duration versus depth relationship derived from our free-living great cormorants (Fig. 4) is typical among diving endotherms (e.g. McIntyre et al. 2010, Zimmer et al. 2010, Doniol-Valcroze et al. 2011, Cook et al. 2012) and is considered to be a result of 2 processes. One process is that, in order to optimise foraging time on the seabed, deeper dives (which have longer transit durations; e.g. Shepard et al. 2009, Cook et al. 2012) should have increasing bottom durations (e.g. Wilson et al. 2011, GómezLaich et al. 2012). However (second process), as total dive durations increase, animals have to spend disproportionately longer periods at the surface recovering from dives (e.g. Butler \& Jones 1997, Wilson \& Quintana 2004, Halsey \& Butler 2006). Thus, as diving endotherms approach (and exceed) their aerobic dive limit (see Butler 2004 for discussion of this), they have to incur a reduction in bottom duration (e.g. Chappell et al. 1993, Kooyman \& Kooyman 1995, Bevan et al. 1997). Our modelled effect of device-induced changes in the bottom duration does not change this process and nor, indeed, does it appreciably change the length of time that great cormorants would be able to stay on the bottom during dives even if these birds do not change swim speed with device size (cf. Wilson et al. 1986).

\section{Scenario 2: Bottom distance penalties associated with maintaining constant power input}

One option suggested for device-equipped diving birds is that they might maintain power input at a constant level during swimming by reducing speed with increasing device size (Wilson et al. 1986, van der Hoop et al. 2014).

Similarly to what has been recently observed for dolphins (van der Hoop et al. 2014), we expect to see a reduction in the swim speed of great cormorants as one strategy to reduce the extra metabolic cost of swimming with a device. This is because at slower speeds, the increase in drag created by a device attached to an animal swimming underwater would decrease and could even be nullified as shown by the computational fluid dynamics model performed by van der Hoop et al. (2014). However, by reducing their swimming speeds and if the amount of energy devoted to one dive is to remain the same as when unequipped, one consequence will be that the dis- 
tance covered by equipped birds will be shorter. More precisely, if great cormorants do this, unequipped birds swimming at $1.4 \mathrm{~m} \mathrm{~s}^{-1}$ would have the same power requirement $(30.23 \mathrm{~W})$ as birds equipped with devices with cross-sectional areas of 1,2 and $4 \mathrm{~cm}^{2}$ swimming at about 1.37, 1.34 and $1.30 \mathrm{~m} \mathrm{~s}^{-1}$, respectively. The distance that these birds would cover during the bottom phase of their dives (derived by multiplying the swim speed by the bottom duration taken from Eq. 8) decreases by ca. 2.1, 4.3 and $7.1 \%$ compared to the unequipped birds, for birds wearing the smaller to the larger devices, respectively (Fig. 5B). If distance swum equates to number of prey encountered or to the probability that prey will be encountered (see Wilson et al. 1996), great cormorants reducing speed to maintain power use during diving may substantially affect their foraging capacity when carrying external devices of the size modelled here.

\section{Scenario 3: Capacity for burst swimming in prey pursuit}

Some studies note that great cormorants catch prey underwater after a pursuit phase (Ashmole 1971, Cooper 2008), during which time speeds may greatly exceed the mean values used in the present study (Table 1), with some speed estimates being as high as $4 \mathrm{~m} \mathrm{~s}^{-1}$ (Wilson \& Wilson 1988, Ropert-Coudert et al.

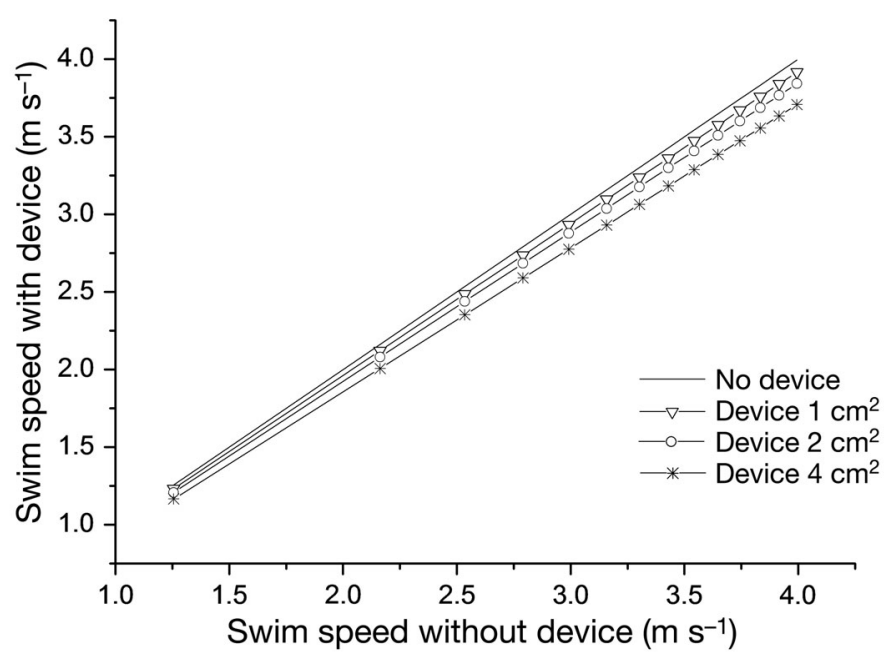

Fig. 6. Predicted power equivalence speeds for great cormorants swimming underwater with variously sized devices. Continuous bold line: an unequipped bird (to highlight the difference between encumbered and unencumbered birds); lines with triangles, circles and stars: birds wearing devices with cross-sectional areas of 1,2 and $4 \mathrm{~cm}^{2}$, respectively.

Note the increasing divergence with increasing speed
2006). Our model of the effect of attached devices allows us to equate the power used by an unequipped bird to swim at any given speed with the speeds that variously equipped birds could swim at for that power. This speed equivalence approach (Fig. 6) showed increasing disparity between equipped and unequipped birds with increasing speed such that, for example, a great cormorant equipped with a device with a cross-sectional area of $4 \mathrm{~cm}^{2}$ could not even reach the $4 \mathrm{~m} \mathrm{~s}^{-1}$ speed reached by unequipped birds. While a $7 \%$ reduction is more or less appreciable, the possible detriment here lies in the compromised capacity of the bird to catch faster prey. Other things being equal, faster prey tend to be larger, for reasons discussed in Peters (1983), and therefore also represent a greater source of nutrients. In essence, perhaps the most telling detriment to a great cormorant carrying an external tag of the types modelled here lies in the extent to which the birds pursue large, fast prey. In fact, great cormorants consume a wide variety of prey, both in terms of species and size (Harris \& Wanless 1993, Veldkamp 1995, Grémillet et al. 2004), so that e.g. the great cormorants found in Normandy (France), which mainly feed on small fish-like labrids (Grémillet \& Argentin 1998), are unlikely to be substantially affected by the burst-speed power problem whereas great cormorants in Iceland, which can take large sandeels and bull-routs (Lilliendalht \& Solmundsson 2006), certainly will be affected.

\section{Determination of device detriment in cormorants}

Our study highlights a number of important issues in attempts to determine the drag-related detrimental effects of externally attached tags to birds in general, and cormorants in particular. A major finding is that it is inappropriate to extrapolate linearly between device dimensions (here represented by crosssectional area) and device detriment. A device with a cross-sectional area of $4 \mathrm{~cm}^{2}$ constitutes about $3 \%$ of the cross-sectional area of a great cormorant at its maximum point of girth (ca. $127 \mathrm{~cm}^{2}$ ), but this is only predicted to cause a roughly $1.7 \%$ increase in power consumption to swim at normal foraging speeds. However, if the birds maintain power use at a constant level during dives, the same device should reduce the distances travelled along the seabed by some $7.1 \%$, and ultimately make it impossible for the birds to catch prey that can swim faster than $3.5 \mathrm{~m} \mathrm{~s}^{-1}$ (assuming the birds can normally achieve burst speeds of $4 \mathrm{~m} \mathrm{~s}^{-1}$ ). This highlights the dangers of 
simple rules used by ethical bodies to judge the detrimental effects of externally attached tags.

In this regard, 2 factors are critical in the drag issue. One is the drag imposed by the device itself in relation to the drag coefficient of the animal. Published values for the drag coefficients of cormorants, determined by a variety of methods (cf. Lovvorn et al. 2001, Ribak et al. 2005), accord roughly with our estimation of around 0.02 (for a calculated surface area of $0.12 \mathrm{~m}^{2}$ and $\operatorname{Re}=10^{-6}$ ). However, the effect of compliant surfaces (Bannasch 1995, Choi et al. 1997) and precise measurement protocols can lead to appreciable variation in estimates (cf. Lovvorn et al. 2001, Ribak et al. 2005; see Pennycuick 1989 for discussion), so drag values, including ours, need to be treated with caution. Nevertheless, values for cormorant drag are nothing like as low as the surface drag coefficients ascribed to e.g. penguins, which are reported to be of the order of 0.003 (Clark \& Bemis 1979, Bannasch 1995). The lower the drag coefficient of the animal carrier, the more critical the effects of an attached device are likely to be. This may explain why, for example, the simple attachment of a flipper band to penguins increases the energy expenditure for normal swimming by $24 \%$ (Culik et al. 1993), with such dramatic consequences for breeding success and long-term survival (Saraux et al. 2011). Thus, the higher drag estimates for cormorants would seem to make them less susceptible to the deleterious effects of externally attached tags than penguins, but the extent of any detriment will also be critically dependent on speed, attested by the exponentially increasing values of drag with increasing speed (Fig. 2). In this regard it may be no coincidence that studies determining the normal (bottom phase) swim speed of great cormorants using externally attached loggers report values that generally do not exceed $1.4 \mathrm{~m}$ $\mathrm{s}^{-1}$, a point where the effect of such devices appears virtually negligible (Fig. 2), whereas other studies on non-equipped birds report swimming speeds of up to $4 \mathrm{~m} \mathrm{~s}^{-1}$ (Wilson \& Wilson 1988). Thus, the normal lifestyle of the subject animal and the error that can be introduced need to be taken into account.

\section{CONCLUSIONS}

Our integrative study explores how some of the features of great cormorant foraging ecology might change when birds carry external biologging devices. The study highlights the difficulties of both determining the drag and quantifying how the ramifications of increased drag might affect wild birds.
Although the results may indicate that devices of the size we used have a negligible effect on cormorant foraging behaviour, this conclusion needs to be tempered for 2 main reasons: (1) any effect, even if apparently small, needs to be considered over long period of time (Saraux et al. 2011), and (2) the acknowledged, appreciable weaknesses in our methodology. Critically though, our work does show that the animals most likely to be affected by the placement of external loggers are those that habitually swim fast and have low drag coefficients. Based on this, we propose that those investigators wishing to undertake studies on high swim-speed vertebrates estimate (1) the drag coefficients of their subjects, (2) the amount of time devoted to high-speed phases, and (3) whether high speed manoeuvres are critical for e.g. prey acquisition; so as to quantify better the impact of any proposed devices. Considering the great number of studies using externally-attached biologging technology, this approach would provide essential information for best practise in biologging.

Acknowledgements. We are grateful to Clive Francis (the 'Q' of Swansea University) for making the model cormorant; to Dr. Onur Bilgen for his assistance with the wind tunnel, and to Dr. Norman Day for his assistance with the cormorant trials. This work was supported by a number of grants received from the Natural Environment Research Council, $\mathrm{UK}_{i}$ the French Polar Institute IPEV and CNRS; and the Oiled Wildlife Care Network and Royal Society for Prevention of Cruelty to Animals.

\section{LITERATURE CITED}

Ashmole N (1971) Seabird ecology and the marine environment. In: Farner DS, King JR (eds) Avian biology, Book I. Academic Press, New York, NY, p 224-271

Bannasch R (1995) Hydrodynamics of penguins - an experimental approach. In: Dann P, Norman I, Reilly P (eds) The penguins: ecology and management. Proc 2nd Int Penguin Conf, Cowes, Phillip Island, 1992. Surrey Beatty \& Sons, Chipping Norton, NSW, p 141-176

Bannasch R, Wilson RP, Culik B (1994) Hydrodynamic aspects of design and attachment of a back-mounted device in penguins. J Exp Biol 194:83-96

Barron DG, Brawn JD, Weatherhead PJ (2010) Meta-analysis of transmitter effects on avian behaviour and ecology. Methods Ecol Evol 1:180-187

> Bevan R, Boyd I, Butler P, Reid K, Woakes A, Croxall J (1997) Heart rates and abdominal temperatures of free-ranging South Georgian shags, Phalacrocorax georgianus. J Exp Biol 200:661-675

Bowlin MS, Henningsson P, Muijres FT, Vleugels RH, Liechti F, Hedenström A (2010) The effects of geolocator drag and weight on the flight ranges of small migrants. Methods Ecol Evol 1:398-402

Butler PJ (2004) Metabolic regulation in diving birds and mammals. Respir Physiol Neurobiol 141:297-315

Butler PJ, Jones DR (1997) Physiology of diving of birds and 
mammals. Physiol Rev 77:837-899

Calvo B, Furness R (1992) A review of the use and the effects of marks and devices on birds. Ringing Migr 13:129-151

Chappell MA, Shoemaker VH, Janes DN, Bucher TL, Maloney SK (1993) Diving behavior during foraging in breeding Adélie penguins. Ecology 74:1204-1215

Choi KS, Yang X, Clayton B, Glover E, Atlar M, Semenov B, Kulik V (1997) Turbulent drag reduction using compliant surfaces. Proc R Soc Lond A Math Phys Eng Sci 453: 2229-2240

Clark B, Bemis W (1979) Kinematics of swimming of penguins at the Detroit Zoo. J Zool 188:411-428

> Cook TR, Hamann M, Pichegru L, Bonadonna F, Grémillet D, Ryan PG (2012) GPS and time-depth loggers reveal underwater foraging plasticity in a flying diver, the Cape cormorant. Mar Biol 159:373-387

> Cooke SJ, Hinch SG, Wikelski M, Andrews RD, Kuchel LJ, Wolcott TG, Butler PJ (2004) Biotelemetry: a mechanistic approach to ecology. Trends Ecol Evol 19:334-343

> Cooper J (2008) Diving patterns of cormorants Phalacrocoracidae. Ibis 128:562-570

Culik B, Wilson RP (1991) Swimming energetics and performance of instrumented Adélie penguins (Pygoscelis adeliae). J Exp Biol 158:355-368

Culik B, Wilson RP, Bannasch R (1993) Flipper-bands on penguins: What is the cost of a life-long commitment? Mar Ecol Prog Ser 98:209-214

> Doniol-Valcroze T, Lesage V, Giard J, Michaud R (2011) Optimal foraging theory predicts diving and feeding strategies of the largest marine predator. Behav Ecol 22: 880-888

Elliott KH, Le Vaillant M, Kato A, Speakman JR, RopertCoudert Y (2013) Accelerometry predicts daily energy expenditure in a bird with high activity levels. Biol Lett 9: 20120919

- Enstipp MR, Ciccione S, Gineste B, Milbergue M and others (2011) Energy expenditure of freely swimming adult green turtles (Chelonia mydas) and its link with body acceleration. J Exp Biol 214:4010-4020

> Gleiss AC, Wilson RP, Shepard ELC (2011) Making overall dynamic body acceleration work: on the theory of acceleration as a proxy for energy expenditure. Methods Ecol Evol 2:23-33

Gómez-Laich AG, Wilson RP, Gleiss AC, Shepard ELC, Quintana F (2011) Use of overall dynamic body acceleration for estimating energy expenditure in cormorants: Does locomotion in different media affect relationships? J Exp Mar Biol Ecol 399:151-155

Gómez-Laich AG, Quintana F, Shepard ELC, Wilson RP (2012) Intersexual differences in the diving behaviour of imperial cormorants. J Ornithol 153:139-147

Green JA, Tanton JL, Woakes AJ, Boyd IL, Butler PJ (2004) Effects of long-term implanted data loggers on macaroni penguins Eudyptes chrysolophus. J Avian Biol 35:370376

Green JA, Halsey LG, Wilson RP, Frappell PB (2009) Estimating energy expenditure of animals using the accelerometry technique: activity, inactivity and comparison with the heart-rate technique. J Exp Biol 212: 471-482

Grémillet D, Argentin G (1998) Cormorants, shags and fisheries in the Chausey Islands area. Le Cormoran 10: 196-202

Grémillet D, Wilson RP, Storch S, Gary Y (1999) Threedimensional space utilization by a marine predator. Mar Ecol Prog Ser 183:263-273
Grémillet D, Wright G, Lauder A, Carss DN, Wanless S (2003) Modelling the daily food requirements of wintering great cormorants: a bioenergetics tool for wildlife management. J Appl Ecol 40:266-277

Grémillet D, Kuntz G, Delbart F, Mellet M and others (2004) Linking the foraging performance of a marine predator to local prey abundance. Funct Ecol 18:793-801

Grémillet D, Kuntz G, Woakes AJ, Gilbert C, Robin JP, Le Maho Y, Butler PJ (2005) Year-round recordings of behavioural and physiological parameters reveal the survival strategy of a poorly insulated diving endotherm during the Arctic winter. J Exp Biol 208:4231-4241

Halsey LG, Butler PJ (2006) Optimal diving behaviour and respiratory gas exchange in birds. Respir Physiol Neurobiol 154:268-283

Halsey L, Bost CA, Handrich Y (2007) A thorough and quantified method for classifying seabird diving behaviour. Polar Biol 30:991-1004

Halsey LG, Shepard ELC, Quintana F, Gómez-Laich A, Green JA, Wilson RP (2009) The relationship between oxygen consumption and body acceleration in a range of species. Comp Biochem Physiol A Mol Integr Physiol 152:197-202

> Harris M, Wanless S (1993) The diet of shags Phalacrocorax aristotelis during the chick-rearing period assessed by three methods. Bird Study 40:135-139

> Kooyman G, Kooyman T (1995) Diving behavior of emperor penguins nurturing chicks at Coulman Island, Antarctica. Condor 97:536-549

> Lilliendahl K, Solmundsson J (2006) Feeding ecology of sympatric European shags Phalacrocorax aristotelis and great cormorants $P$. carbo in Iceland. Mar Biol 149: 979-990

Lovvorn J (1999) Effects of dive depth, buoyancy, and propulsive mode on the inertial work of swimming in birds. Am Zool 39:14

Lovvorn J, Liggins GA, Borstad MH, Calisal SM, Mikkelsen J (2001) Hydrodynamic drag of diving birds: effects of body size, body shape and feathers at steady speeds. J Exp Biol 204:1547-1557

McIntyre T, Tosh CA, Plötz J, Bornemann H, Bester MN (2010) Segregation in a sexually dimorphic mammal: a mixed-effects modelling analysis of diving behaviour in southern elephant seals. Mar Ecol Prog Ser 412:293-304

Obrecht H, Pennycuick C, Fuller M (1988) Wind tunnel experiments to assess the effect of back-mounted radio transmitters on bird body drag. J Exp Biol 135:265-273

Orme JAC, Masters I, Griffiths RT (2001) Investigation of the effect of biofouling on the efficiency of the marine current turbines. Proc Marine Renewable Energy Conf, 2001, March 27-28, Newcastle, p 91-99

Paredes R, Jones IL, Boness DJ (2005) Reduced parental care, compensatory behaviour and reproductive costs of thick-billed murres equipped with data loggers. Anim Behav 69:197-208

Pennycuick CJ (1989) Bird flight performance: a practical calculation manual. Oxford University Press, Oxford

Pennycuick C, Fast PL, Ballerstädt N, Rattenborg N (2012) The effect of an external transmitter on the drag coefficient of a bird's body, and hence on migration range, and energy reserves after migration. J Ornithol 153:633-644

Peters RH (1983) The ecological implications of body size, Vol 2. Cambridge University Press, Cambridge

Ribak G, Weihs D, Arad Z (2005) Submerged swimming of the great cormorant Phalacrocorax carbo sinensis is a 
variant of the burst-and-glide gait. J Exp Biol 208: 3835-3849

Ritchie W, Green J, Dann P, Butler P, Frappell P (2010) Do implanted data-loggers affect the time spent at sea by little penguins (Eudyptula minor) during winter? Emu 110:71-77

Ropert-Coudert Y, Wilson RP (2005) Trends and perspectives in animal-attached remote sensing. Front Ecol Environ 3:437-444

Ropert-Coudert Y, Grémillet D, Kato A (2006) Swim speeds of free-ranging great cormorants. Mar Biol 149:415-422

Ross RK (1976) Notes on the behavior of captive great cormorants. Wilson Bulletin 16:143-145

Rutz C, Hays GC (2009) New frontiers in biologging science. Biol Lett 5:289-292

Saraux C, Le Bohec C, Durant JM, Viblanc VA and others (2011) Reliability of flipper-banded penguins as indicators of climate change. Nature 469:203-206

Sato K, Naito Y, Kato A, Niizuma Y and others (2002) Buoyancy and maximal diving depth in penguins: Do they control inhaling air volume? J Exp Biol 205:1189-1197

Schmid D, Grémillet D, Culik B (1995) Energetics of underwater swimming in the great cormorant (Phalacrocorax carbo sinensis). Mar Biol 123:875-881

Shepard ELC, Wilson RP, Halsey LG, Quintana F and others (2008) Derivation of body motion via appropriate smoothing of acceleration data. Aquat Biol 4:235-241

Shepard ELC, Wilson RP, Quintana F, Gómez-Laich A, Forman DW (2009) Pushed for time or saving on fuel: finescale energy budgets shed light on currencies in a diving bird. Proc R Soc Lond B Biol Sci 276:3149-3155

Tremblay Y, Cook TR, Cherel Y (2005) Time budget and diving behaviour of chick-rearing Crozet shags. Can J Zool 83:971-982

van der Hoop JM, Fahlman A, Hurst T, Rocho-Levine J, Shorter KA, Petrov V, Moore MJ (2014) Bottlenose dolphins modify behavior to reduce metabolic effect of tag attachment. J Exp Biol 217:4229-4236

Vandenabeele SP, Wilson RP, Grogan A (2011) Tags on seabirds: How seriously are instrument-induced behaviours considered? Anim Welf 20:559-571

Veldkamp R (1995) Diet of cormorants Phalacrocorax carbo sinensis at Wanneperveen, the Netherlands, with special reference to bream Abramis brama. Ardea 83:143-155

Voslamber B, Van Eerden MR (1991) The habit of mass flock fishing by cormorants Phalacrocorax carbo sinensis at the Ijsselmeer, The Netherlands. In: Van Eerden MR, Zijlstra M (eds) Proc Workshop 1989 on cormorants Phalacrocorax carbo, Lelystad, The Netherlands

Wanless S, Corfield T, Harris M, Buckland S, Morris J (1993) Diving behaviour of the shag Phalacrocorax aristotelis (Aves: Pelecaniformes) in relation to water depth and prey size. J Zool (Lond) 231:11-25

Editorial responsibility: Scott Shaffer,

San Jose, California, USA
Watanuki Y, Niizuma Y, Geir WG, Sato K, Naito Y (2003) Stroke and glide of wing-propelled divers: deep diving seabirds adjust surge frequency to buoyancy change with depth. Proc R Soc Lond B Biol Sci 270:483-488

> Watanuki Y, Wanless S, Harris M, Lovvorn JR, Miyazaki M, Tanaka H, Sato K (2006) Swim speeds and stroke patterns in wing-propelled divers: a comparison among alcids and a penguin. J Exp Biol 209:1217-1230

> Watanuki Y, Daunt F, Takahashi A, Newell M, Wanless S, Sato K, Miyazaki N (2008) Microhabitat use and prey capture of a bottom-feeding top predator, the European shag, shown by camera loggers. Mar Ecol Prog Ser 356: 283-293

Watson KP, Granger RA (1998) Hydrodynamic effect of a satellite transmitter on a juvenile green turtle (Chelonia mydas). J Exp Biol 201:2497-2505

White CR, Day N, Butler PJ, Martin GR (2007) Vision and foraging in cormorants: More like herons than hawks? PLoS ONE 2:e639

Wilson RP, Quintana F (2004) Surface pauses in relation to dive duration in imperial cormorants; How much time for a breather? J Exp Biol 207:1789-1796

> Wilson RP, Wilson MP (1988) Foraging behaviour in four sympatric cormorants. J Anim Ecol 57:943-955

Wilson RP, Wilson MPT (1989) Tape: a package-attachment technique for penguins. Wildl Soc Bull 17:77-79

> Wilson RP, Zimmer I (2004) Inspiration by Magellanic penguins: reduced swimming effort when under pressure. Mar Ecol Prog Ser 278:303-307

> Wilson RP, Grant WS, Duffy DC (1986) Recording devices on free-ranging marine animals: Does measurement affect foraging performance? Ecology 67:1091-1093

Wilson RP, Wilson MPT, Nöldeke EC (1992) Pre-dive leaps in diving birds; Why do kickers sometimes jump? Mar Ornithol 20:7-16

Wilson RP, Culik B, Peters G, Bannasch R (1996) Diving behaviour of Gentoo penguins, Pygoscelis papua; factors keeping dive profiles in shape. Mar Biol 126:153-162

Wilson RP, Kreye J, Lucke K, Urquhart H (2004) Antennae on transmitters on penguins: balancing energy budgets on the high wire. J Exp Biol 207:2649-2662

Wilson RP, White C, Quintana F, Halsey L, Liebsch N, Martin G, Butler P (2006) Moving towards acceleration for estimates of activity specific metabolic rate in free living animals: the case of the cormorant. J Anim Ecol 75: 1081-1090

Wilson RP, McMahon CR, Quintana F, Frere E, Scolaro A, Hays GC, Bradshaw CJA (2011) N-dimensional animal energetic niches clarify behavioural options in a variable marine environment. J Exp Biol 214:646-656

Zimmer I, Wilson RP, Beaulieu M, Ropert-Coudert Y, Kato A, Ancel A, Plötz J (2010) Dive efficiency versus depth in foraging emperor penguins. Aquat Biol 8:269-277

Submitted: March 19, 2014; Accepted: September 28, 2014

Proofs received from author(s): December 9, 2014 